\title{
Comparative Effectiveness of Life Skills Training, Voluntary Service Work and Homeopathic Treatment on Individuals Self-Esteem
}

\author{
Mandana Bagherian'1, Adis Kraskian Mojembari' ${ }^{1}$ Ahmad Borjali², Mohammad Hakami1 \\ ${ }^{1}$ Islamic Azad University, Karaj Branch, Karaj, Iran \\ ${ }^{2}$ Alameh Tabatabaii University, Tehran, Iran \\ Email: satyba@gmail.com
}

How to cite this paper: Bagherian, M., Mojembari, A. K., Borjali, A., \& Hakami, M. (2016). Comparative Effectiveness of Life Skills Training, Voluntary Service Work and Homeopathic Treatment on Individuals SelfEsteem. Psychology, 7, 1796-1809. http://dx.doi.org/10.4236/psych.2016.714167

Received: October 30, 2016

Accepted: December 2, 2016

Published: December 5, 2016

Copyright $\odot 2016$ by authors and Scientific Research Publishing Inc. This work is licensed under the Creative Commons Attribution International License (CC BY 4.0).

http://creativecommons.org/licenses/by/4.0/ (c) (i) Open Access

\section{Abstract}

The aim of the present study is to compare the efficacy of three therapeutic strategies: life skills, Homeopathic treatment as well as voluntary service work to enhance self-esteem. The population consisted of 90 people (61 women and 29 men) ranging between 16 and 40 years old who were selected by random sampling method. This is a quasi-experimental test, and the statistical method is to calculate the means of three independent groups. The mean score of post-test and follow-up score in experimental groups have been compared and evaluated, using an average of two affiliates. The results show that life skills training is effective in increasing self-esteem besides its components and it has a lasting effect. Doing voluntary service work is effective in increasing self-esteem and its components (except for the family's self-esteem), but it does not have a stable effect. Homeopathic treatment is effective in increasing selfesteem as well as its components (except for family's self-esteem), and it has a stable effect. A comparative study of the three approaches shows that the efficacy of life skills training in increasing public and family self-esteem is more than the effectiveness of voluntary service work and homeopathic treatment (the efficacy of voluntary service work and homeopathic treatment in increasing public and family self-esteem is similar).The effectiveness of life skills training, voluntary service work and homeopathic treatment in increasing the social and occupational self-esteem is equal. The efficacy of life skills training in increasing self-esteem (total score) is more than that for voluntary service work.

\section{Keywords}

Life Skills, Voluntary Service Work, Homeopathy, Self-Esteem 


\section{Introduction}

Self-esteem is in fact, the judgment we make about our value and the feeling we have about this judgment. Self-concept is, a series of attributes, abilities, attitudes, and values that an individual believes other people will characterise him by them, and self-esteem can be seen as another aspect of self-concept that appears in early childhood (Berk, 2007). Self-esteem usually forms in children when they are 3 years old and during relatively difficult assignments. Children whose parents have high expectations of them or blame them, when faced with their assignments, will quickly give up trying and after the defeat, they get frustrated (Kelly, Brunel, Campbell, 2000; Berk, 2007).

According to Maslow, the human psychologist, one of the basic human needs is the need for self-esteem or self-respect which includes the feelings of competence, adequacy and skillfulness. Having said that, an individual needs to create a positive image of himself in others (Maslow, Seif, 1997). According to Coopersmith (1967), self-esteem is a personal judgment about worthiness or worthlessness, and self-acceptance or nonacceptance, which appears in people's attitudes (Biabangard, 1994). Shamloo (2003), believes that, self-esteem consists of, a continuous evaluation of an individual's selfworth, and a personal judgment about existential worthiness.

Rogers defined self-esteem as continuous assessment of a person's self-worth or a kind of value judgment about their existence. He believes that this trait in humans is general and not limited or transient. According to Rogers, self-esteem arises from the need for positive attention of others. The need for positive attention of others includes, feedback, warm and affectionate attitude, intimacy, acceptance and kindness of the others, especially children's parents (Shamloo, 1990).

Until recently, researchers and theorists, considered self-esteem an overall selfjudgment, but it has been found, in recent years, that children and adults judge and evaluate themselves from different perspectives, such as social, physical, educational, family and general perspectives.

Cooper Smith, introduces the dimensions of self-esteem as:

\subsection{Educational Self-Esteem}

Educational self-esteem is related to an individual's judgment and evaluation according to their educational value. If people react favourably to the person's educational status, it creates a self-satisfaction and helps the person to judge themselves positively.

\subsection{Social Self-Esteem}

Includes individuals' beliefs about themselves as friends to others. Do others like him? Are his beliefs and thoughts valuable to them? Will they let him participate in their activities? Does he feel happy communicating and interacting with his peers? In general, a person whose social needs are met, regardless of how many of them correspond to national traditions and accepted principles, will have a good feeling in this respect. 


\subsection{Physical Self-Esteem}

Physical self-esteem is referred to person's assessment and belief in their physical ability that is achieved through physical activities and actions. So, if a person is in good physical ability and health, it will have positive effect on their physical self-esteem. Whereas, physical disabilities and inability to perform activities and skills will have negative effects on an individual's physical self-esteem.

\subsection{Family Self-Esteem}

Assessment and judgment of an individual as a member of family is called family self-esteem that is created by the interaction of the individual with their family members. The interaction of the person with their parents and siblings or other family members, and how much they are accepted by them, can be effective in their attitudes toward themselves, and this will determine their family self-esteem.

\subsection{General Self-Esteem}

General self-esteem refers to the individual's assessment and judgment about their values. This aspect of self-esteem includes all the above-mentioned aspects and in fact, it gives them some of kind of unity. Individuals who possess positive general self-esteem, consider themselves good and favourable in all physical, social, family and educational aspects. They achieve their positive reactions from the positive reactions of family members, peers, teachers and their physical abilities. Such types of people can cope with their problems more successfully (Biabangard, 1994; Seif, 2007).

\subsection{Life Skills}

The World Health Organization (1994) has identified the following ten skills:

Self-awareness Skill: self-awareness skill is the ability to identify the strengths and weaknesses of demands, needs, desires, and realistic self-image to better understand our individual social rights and responsibilities. By acquiring this skill, we can answer the basic question "Who am I?".

Empathy Skill: Empathy means, the individuals can understand and respect other people's problems even when they are not in that situation. This skill makes us pay attention to others and love them and be loved by others in order to be closer to each other by establishing social relationship.

Interpersonal Skills: It is a skill that while strengthening the spirit of cooperation, realistic trust and collaboration causes us to detect the boundaries of relationship between ourselves and those we love and step toward creating warm and friendly relations, and try to end the inappropriate and unhealthy friendships before we are seriously hurt.

Effective communication skill: Acquiring this skill will teach us how to listen actively to others people's speeches for better understanding their situations and how to make others aware of our feelings and needs; so, while achieving our demands, the others will also be stratified. 
Stress Controlling Skill: In today's world, we constantly encounter vast and complex changes and any kind of change is associated with mental and psychological stress. If the stress is too much and for too long, it will have a negative impact on our lives and performance. Learning this skill will help us to identify different types of stress and their effects, as well as acquiring the ways to reduce and manage them.

Emotion Management Skill: If we can manage our happiness, sadness, anger, despair, anxiety and other emotions well, our dreams, memories and perceptions will come to life. Acquiring this skill will help us to identify our emotions and others and their effects on our thoughts and behaviours, as well as learning how to react appropriately to them.

Problem-Solving Skill: Every day, we are faced with many problems, some simple and some complex. Problem-solving skill gives us the ability to take steps toward solving the problems, according to our academic experience and mental abilities, and to achieve the desired result.

Decision-Making Skill: Human life always requires making various decisions, and the success in life depends on making the right decision. Decision-making skill will help us to select and apply the best solution, with respect to realistic objectives, and we welcome its consequences.

Creative Thinking Skill: Thinking is a skill that we learn in early childhood. Creative thinking skill will provide us with the power of discovering and generating the new ideas. Creative thinking skill will help us to transform the negative feeling into positive ones in the face of disasters. Creative thinking is another kind of seeing. In this type of thinking the problem is never considered a nuisance, but an opportunity to discover new and innovative solutions that no one has, thus far, noticed.

Critical Thinking Skill: Critical thinking is another kind of thinking. Acquiring this skill will teach us not to simply accept or reject everything. We should first inquire or argue about an issue before accepting or rejecting it. Those who possess critical thinking, are not deceived by others and will not be attracted to groups and individuals or narcotics, because they always think about the consequences by asking questions (Fati, 1994. "Saani et al., 2014").

Homeopathy: Homeopathic treatment is a holistic treatment that was first proposed by Samuel Hahnemann in 1976. Hahnemann found that the disease can be treated with the factors similar to the disease and the word homeopathy is derived from this meaning "Similar treatment".

Homeopathy is derived from two words, Homeo which means "Similar" and Pathy derived from the latin word Pathus which means "pain and suffering" and also "treatment". The basic principle underlying this therapeutic method is based on slogan "Similar will treat similar". He found that any drug, which can cause certain symptoms in a healthy person can cause similar symptoms in a patient. Hahnemann believed that a therapy can be effective when the patient is considered holistically. This means that all the levels of a patient, including the body, mind and emotion can give an image to the therapist that represents the totality of the patient. He acknowledged that the dysfunc- 
tion in a patient's body cannot be separated from their soul and mind.

So, the most similar medicine to a patient's totality, can be the best treatment for the patient (Van Woensel \& Vithoulkas, 2010). Personal or natural treatment that is the foundation of homeopathic treatment and is the same as classical homeopathy is based on the principle that the patient's totality or all the symptoms, will determine the medicines and eventually the treatment. In this case, by getting an accurate picture of the patient, which is all physical, psychological and mental symptoms, the most similar drug is administered to the patients. The similar drug for each patient is the one which can cause the same symptoms and complications in a healthy person. This way of treatment does not omit the symptoms but treats them, and the aim is to treat the patient, not the disease.

Since the maximum attention in homeopathy is paid to the soul and mind of the patient, its therapeutic effect is mostly on psychological disorder as well as mental and psychological damages and defects (Hahnemann, 2006).

Since homeopathic treatment has many positive effects on creating a feeling of recovery (Frass, 2015) and also in reducing and treating psychological trauma and disorders, the present research has tried to measure its effect on the normal people's self-esteem.

The aim of this study is to compare the effects of three mentioned factors (life skills, volunteer services and homeopathic remedy) to improve the level of self-esteem. In addition, the consistencies of these variables are estimated. This study wants to show the best way for boosting self-esteem and is the first research which examines these criteria. So, it can consider as a scientific base for the future studies.

\section{Method}

\subsection{Participants}

First, there was a call for participating in a psychology test with collaboration of an institute in Hashtgerd, Karaj. Of all the people ( 83 women and 64 men) who volunteered to participate in the test and were measured by Cooper Smith self-esteem inventory, 90 people (61 women and 29 men) were selected through random sampling. the Subjects were randomly divided into 3 experimental groups (30 each). The first group participated regularly for 3 months in life-skills classes (Self-awareness, stress controlling and self-confidence skills). The second group volunteered to do free services in a nursing home and a day care center in Hashtged, Karaj for 3 months, once a week for 4 hours, and the third group was put under treatment (natural and follow-up treatment) with lifestyle modification. After 3 months, the amount of self-esteem in subjects was measured again and the results were compared together. To measure the effect of therapeutic interventions, the amount of self-esteem in subjects was measured again, after 2 months. During the study, some participants have left their groups. So, at the end, there were 28 persons in life skills group, 23 in voluntary service work group and 29 in homeopathy group. The test was in the form of pre-test, post-test and for calculating the data, the statistical method of calculation of mean, for three independent groups, was 
used. In this research, among a series of workshops on life skills, more emphasis was put on stress controlling, self-awareness and self-confidence skills. To estimate the effectiveness of variables, analysis of covariance is used. For consistency, analysis of twodependence groups mean and to compare the effectiveness of these three variables, analysis of one-way variance (ANOVA) with Scheffe post hoc analysis is used.

It seems that people's evaluation of themselves depends mostly on their amount of stress, understanding, strength, weakness, and self-confidence. In regard to self-confidence discussions, there is an effort to better understand and build the self-concept, self-image and self-efficacy.

\subsection{Charity and Voluntary Work}

Undoubtedly, it was believed that doing charity work voluntarily, would create a feeling of satisfaction and happiness among individuals (Pour Faroukh, 2014). In the present research, there was a significant review of the effect of charity and voluntary work on self-confidence.

\section{Instrumentation}

\section{Cooper Smith Self-Esteem Inventory}

Cooper Smith self-esteem inventory (SEI) consists of 58 items which describe an individual's feelings, beliefs and reactions, and the subjects must answer the questions by marking either of the two boxes "like me (Yes) and unlike me (No)". The items for each subscale include: general scale with 26 items, "social” scale with 8 items, "family" scale with 8 items, "educational" or "occupational" scale with 8 items, and "falsehood" scale with 8 items. Subscale scores and the general score will provide the ability to specify the context in which people have positive image of themselves (Cooper Smith, 1967). The surveys in Iran and outside Iran show that this test has the credibility and an acceptable validity.

Herz and Golan (1999) have reported the coefficient Alpha of 0.88 for the general score of the test. Also, for measuring the validity of total test score and subscale of neuroticism in the Eysenck personality inventory, a negative and significant divergent validity with subscale of introspection, and a positive and significant convergent validity have been obtained. Edmonds et al (2006) have reported the internal consistency coefficient of 0.86 and 0.90 for the Cooper Smith's self-esteem test. Cooper Smith et al (1990) have reported the test-retest-coefficient of 0.88 after five weeks and 0.70 after a year.

Through test-retest method, the reliability coefficient of 0.77 and 0.80 has been reported within four weeks and twelve days. The reported internal consistency coefficient of 0.89 to 0.83 are varied in different studies. Pour Shafie (1991) has reported the coefficient of 0.87 by split-half method. In reviewing the validity of Cooper Smith's test, Sabet (1996) and Nayebi Fard (2003) obtained a positive convergent validity between Cooper Smith's test and Eysenck's self-esteem test. The amount in the research by Sabet was 0.80 and by Nayebi Fard 0.78. The reliability coefficient of this test through test-retest method for girls and boys was respectively reported 0.90 and 0.92 . In the 
present research, the indices for general, family social, occupational components and the total score for self-esteem were respectively $0.524,0.526,0.743,0.530,0.563$

\section{Findings}

Before testing the research hypotheses and answers to the research questions, three points are studied:

\section{1) Normal Distribution of Variables:}

The Kolmogorov-Smirnov test was used. Research data in all four subscales and total score of self-esteem in all four research groups, and in each of the three phases of administration were normally distributed $(P>0.05)$. So, to test the research hypotheses, parametric tests can be used.

\section{2) Validity of research instruments:}

The retest index was used for estimating the reliability of the instrument. In this case, the correlation between pre-test and post-test scores in the control group has been calculated and tested. The indices for the general, family, social and occupational components, and the total score of self-esteem were respectively $0.524,0.526,0.743,0.530$, 0.563 , which were statistically significant $(P<0.01)$. It represents an acceptable credit for the results of research tools in the sample group.

\section{3) Homogeneity of research groups in terms of demographic characteristics:}

Four research groups, in term of demographic characteristics (Gender, education, marital status, occupation and age) were compared, using the chi-square bivariate and one-way analysis of variance (ANOVA). The results indicated the homogeneity of groups in regard to the above variables $(P>0.05)$

\section{Data Analysis}

The mean and standard deviation scores of self-esteem in four research groups and three rounds of administration are reported in Table 1.

\section{Research Hypotheses Tests}

1)To evaluate the effectiveness of each of the triple interventions, the average scores of each component for pre-test and post-test in related group and control group were compared, using the one-way, univariate analysis of variance (ANOVA). The Summary results of default covariance, analysis of covariance, modified post-tests, and the effect of intervention are indicated in Table 2.

\subsection{Research Results of Effectiveness of Three Variables}

- Life skills training is effective in increasing self-esteem, and its components

- Voluntary service work is effective in increasing self-esteem and its components (except family self-esteem).

- Homeopathic treatment is effective in increasing self-esteem and its components (except family self-esteem).

2) To evaluate the stability of the effect of interventions, the mean scores of the 
post-test follow-up scores in the experimental group were compared and tested, using a T-test for two dependent groups (with paired differences scores). The results are reported in Table 3.

\subsection{Research Results of Consistencies of Three Variables Effectiveness}

- Life-skills training has stable effects on increasing self-esteem and its components over time.

- Voluntary service work does not have a stable effect on increasing self-esteem and its components over time.

- Homeopathic treatment has stable effect on increasing self-esteem and its components over time.

3)To evaluate the efficacy of three intervention research, the differential mean scores (pre-test and post-test scores differences) in three experimental groups were compared together, using one-way analysis of variance (ANOVA) and Scheffa's post hoc analysis. The results are indicated in Table 4.

Table 1. Mean and standard deviation scores of self-esteem.

\begin{tabular}{|c|c|c|c|c|c|c|c|c|}
\hline \multirow{2}{*}{ Self-esteem } & \multirow{2}{*}{ Group } & \multirow{2}{*}{$\underline{\mathrm{n}}$} & \multicolumn{2}{|c|}{ Pre-test } & \multicolumn{2}{|c|}{ Post-test } & \multicolumn{2}{|c|}{ Follow-up } \\
\hline & & & $\underline{M}$ & $\underline{\mathrm{SD}}$ & $\underline{M}$ & $\underline{\mathrm{SD}}$ & $\underline{M}$ & $\underline{\mathrm{SD}}$ \\
\hline \multirow{4}{*}{ General } & Life Skills & 28 & 14.04 & 3.96 & 20.46 & 3.20 & 21.39 & 2.66 \\
\hline & Voluntary Service work & 23 & 18.30 & 5.11 & 21.22 & 2.19 & 19.48 & 2.17 \\
\hline & Homeopathic & 29 & 17.59 & 5.54 & 20.59 & 4.23 & 21.17 & 3.49 \\
\hline & Control & 30 & 17.67 & 4.66 & 17.37 & 3.93 & & \\
\hline \multirow{4}{*}{ Family } & Life Skills & 28 & 4.07 & 2.09 & 5.04 & 1.90 & 5.07 & 1.84 \\
\hline & Voluntary Service work & 23 & 4.26 & 1.48 & 4.48 & 1.31 & 4.52 & 1.28 \\
\hline & Homeopathic & 29 & 3.62 & 1.59 & 3.79 & 1.42 & 3.93 & 1.53 \\
\hline & Control & 30 & 5.17 & 1.64 & 5.03 & 1.47 & & \\
\hline \multirow{4}{*}{ Social } & Life Skills & 28 & 4.68 & 1.59 & 6.25 & 1.11 & 6.54 & 0.92 \\
\hline & Voluntary Service work & 23 & 4.78 & 1.41 & 6.13 & 1.36 & 5.17 & 1.37 \\
\hline & Homeopathic & 29 & 4.90 & 1.92 & 6.76 & 1.15 & 6.77 & 1.30 \\
\hline & Control & 30 & 4.80 & 1.67 & 4.30 & 1.42 & & \\
\hline \multirow{4}{*}{ Occupational } & Life Skills & 28 & 4.54 & 1.71 & 6.29 & 1.61 & 6.36 & 1.39 \\
\hline & Voluntary Service work & 23 & 5.09 & 1.54 & 6.57 & 0.99 & 5.78 & 1.57 \\
\hline & Homeopathic & 29 & 4.83 & 1.58 & 6.45 & 1.59 & 6.69 & 1.56 \\
\hline & Control & 30 & 4.93 & 1.57 & 5.13 & 1.04 & & \\
\hline \multirow{4}{*}{ Total Score } & Life Skills & 28 & 27.39 & 7.00 & 38.00 & 5.42 & 39.36 & 4.25 \\
\hline & Voluntary Service work & 23 & 32.43 & 8.37 & 38.39 & 3.88 & 34.61 & 4.11 \\
\hline & Homeopathic & 29 & 30.59 & 9.13 & 38.55 & 7.46 & 38.93 & 6.68 \\
\hline & Control & 30 & 32.57 & 7.34 & 31.83 & 5.29 & & \\
\hline
\end{tabular}


Table 2. Summary analysis of covariance [To evaluate the effectiveness of interventions].

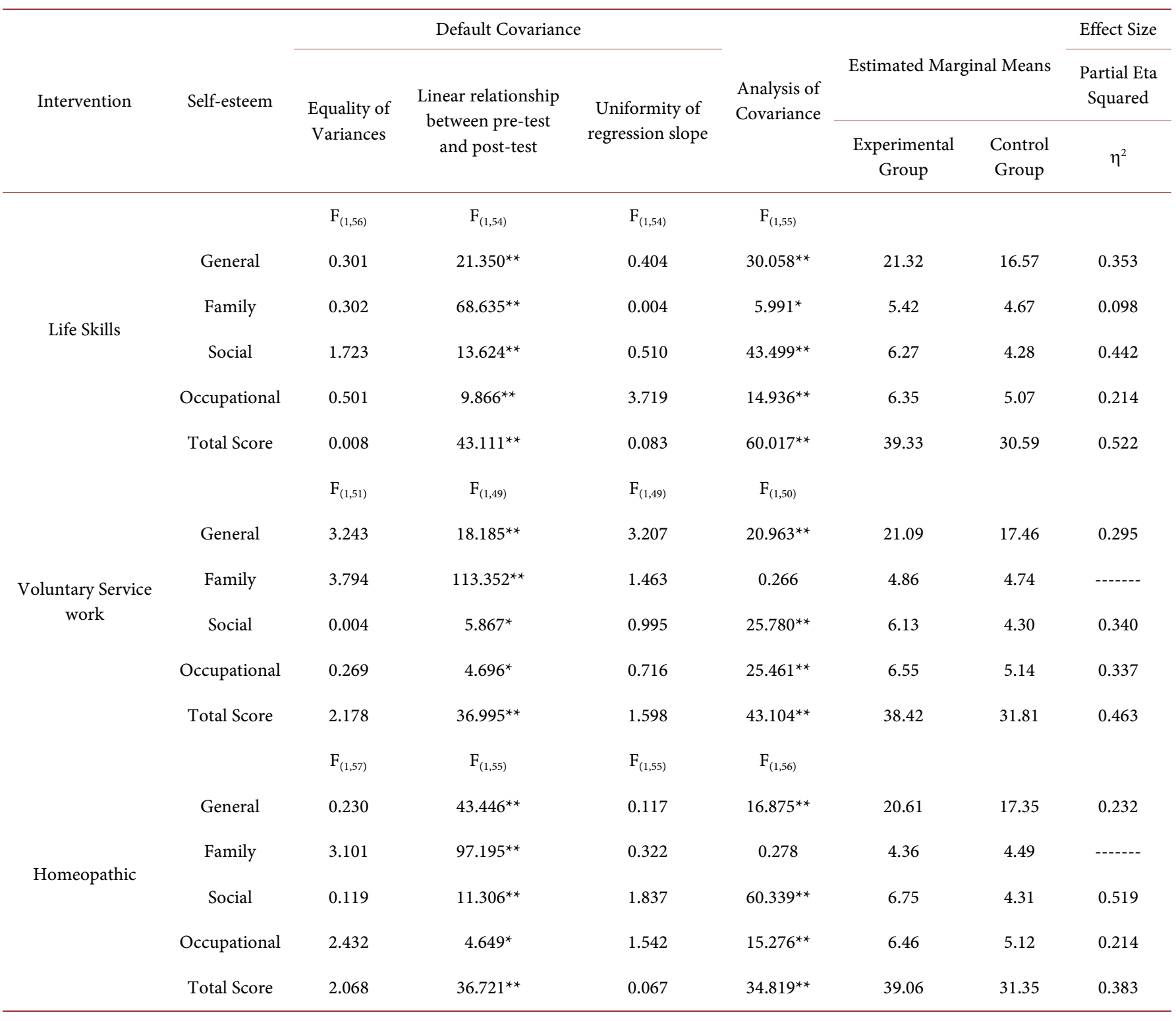

${ }^{*} p<0.05,{ }^{* *} p<0.01$.

Table 3. Summary results of the T-test for two dependent groups (to evaluate the stability effect of interventions).

\begin{tabular}{|c|c|c|c|c|c|c|c|c|c|c|}
\hline Interventions & \multicolumn{10}{|c|}{ Self-esteem } \\
\hline Life Skills & -0.93 & 0.079 & -0.04 & 0.326 & -0.29 & 0.147 & -0.07 & 0.764 & -1.36 & 0.051 \\
\hline Homeopathic & -0.59 & 0.188 & ------- & ------- & -0.01 & 0.999 & -0.24 & 0.214 & -0.38 & 0.602 \\
\hline
\end{tabular}

${ }^{*} p<0.05,{ }^{* *} p<0.01$. 
Table 4. Summary results of one-way ANOVA and Scheffe's Post hoc analysis of differential score [to evaluate the efficacy of intervention].

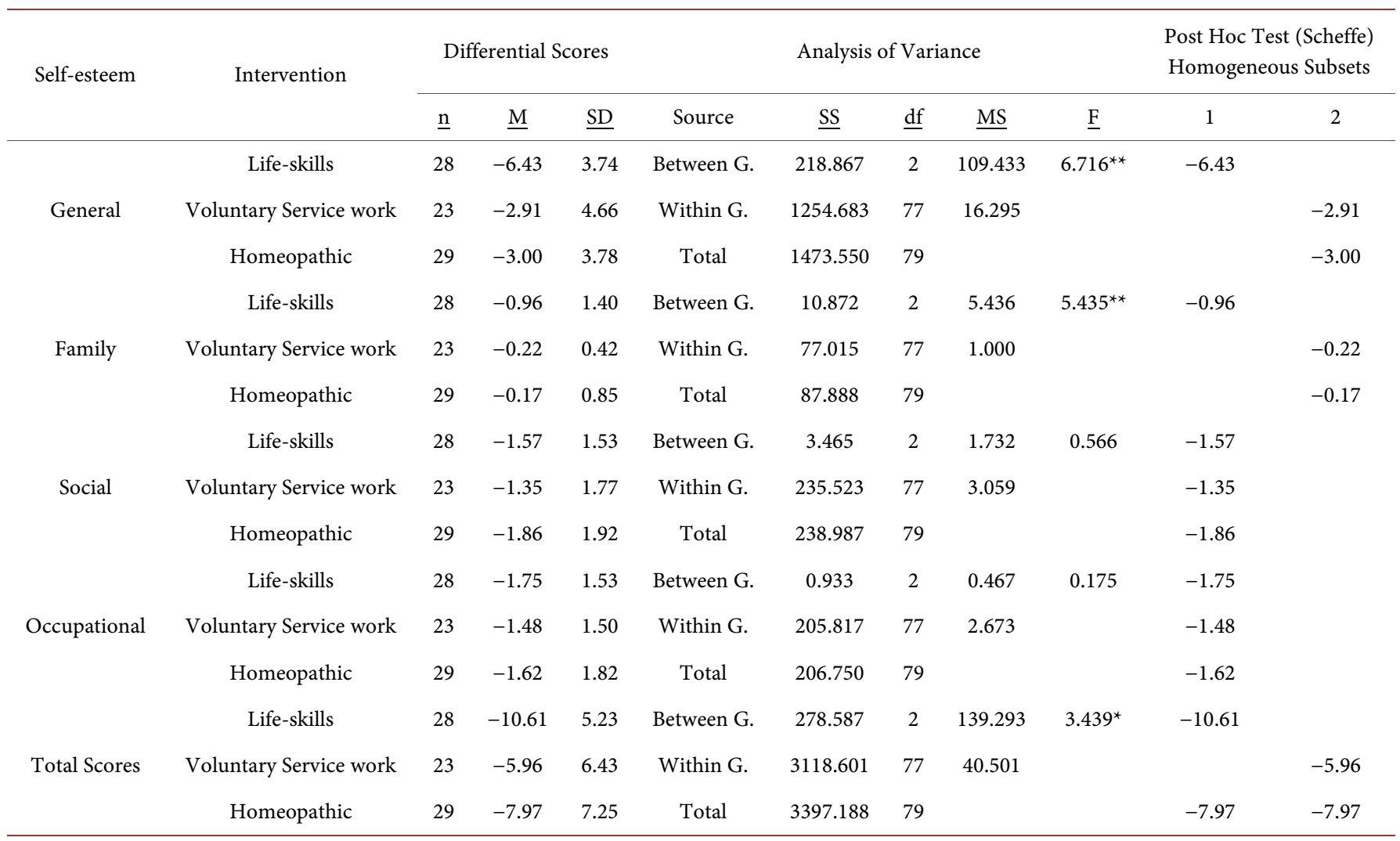

${ }^{*} p<0.01 ;{ }^{*} p<0.05$.

\subsection{Research Results of Comparing Three Variables Both Effectiveness and Consistency}

- The efficacy of life-skills training on increasing the general and family self-esteem is more than that of voluntary service work and homeopathic treatment (The efficacy of voluntary service work and homeopathic treatment on increasing general and family self-esteem is identical).

- The efficacy of life skills training, voluntary service work and homeopathic treatment on increasing social and occupational self-esteem is identical.

- The effectiveness of life-skills training on increasing self-esteem (total score) is more than that of voluntary service work.

\section{Discussion}

This study aims to prove the efficacy of interventions in life-skills, homeopathy and voluntary service work and charity, as well as investigating these three variables in the long run and determining their long-term stability. As the results indicate, all three variables can increase the self-esteem, whereas, their rates of stability and efficacy are different. What can be rightly concluded from the results is that family self-esteem, which is involved from birth to the complete formation of an individual's personality, received 
the least effect. As can be inferred from the findings in this research, acquiring life-skills can increase the self-esteem in either the subscales or total score; this can emphasize the significance of life-skills training for individuals. It is interesting to know that the efficacy of all three variables in this study on the self-esteem of the individuals is the same, but this effect is not stable for charitable and voluntary work.

Life Skills: Numerous studies have shown a correlation between self-esteem and self-concept (Srivastava \& Joshi, 2014). Research has shown that self-esteem cab be considered as the main component of self-concept (Greenwald \& Bellezza Banaji, 1988). There is a positive significant correlation between self-esteem and self-image (Ghanbarinezhad \& Zarinbakhsh, 2015). Also, there is a direct correlation between self-esteem and self-efficacy (Amozadeh, 2012).

Another research indicates the direct and significant effect of self-esteem on self-efficacy and general efficacy of primary school teachers (Khan et al. 2015). From the correlation between self-esteem and self-awareness, we can note the research carried out on narcissistic people. The results suggest that self-esteem instability in narcissistic individuals shows a significant decrease, using individual self-awareness programs (Rhodewalt, Madrian, \& Cheney, 1998). The results of study by Ghasemizadeh et al. (2000), indicate a negatively significant correlation between self-esteem and stress.

The research by Galanakis et al. (2016) indicates that, in addition to the direct interaction of stress and self-esteem, i.e. the effects of stress on self-esteem and the self-esteem on the amount of stress in individuals, learning the stress management strategies can not only increase the self-esteem in individuals, but also increase the amount of it among them. Serving the people and voluntary and charitable work can be effective in improving self-esteem, as well as establishing and maintaining a sense of recovery (Thoits \& Hewitt, 2007). The subjects will learn each skill in 6 sessions, and will be familiar with theoretical concepts and methods. Then, the subjects practice each skill for two sessions to register the skills learned and show how to use and apply them in different situations.

Homeopathy: Numerous research was done on the efficacy of this branch of medicine on physical and mental diseases. Davidson \& Morrison (2012) studied the interventional effect of homeopathy on treating social anxiety, panic disorders and depression. The results of this study showed the efficacy of homeopathic treatment in improving these disorders. Furthermore, the results of the research by Hamann et al. (2014) indicate the high efficacy of herbal medicines and homeopathy in treating mood disorders, including anxiety.

The studies by Montanaro, Fabio, Coppola and Luigi (2013) showed similar results in treating sleep disorders and anxiety by the help of homeopathic drugs. Adler et al. (2013), in a study showed a significant decrease of depression in individuals, through homeopathic intervention. However, no clinical or significant symptoms were observed as a result of treatment with homeopathic medicines compared to treatment with placebo, which need further examinations and studies. In a comparative study that was done for comparing the clinical effects of homeopathy and conventional medicine, 110 
research treatments by homeopathic method were compared and analyzed with 110 research treatments by conventional drugs. Among the selected studies, 65 mean studies were examined. 21 treatments through homeopathic method, and 8 treatments through conventional drugs had the highest therapeutic quality. Among the high-quality treatments, the ratio of homeopathic treatment was 0.88 (1.19\% - 65\% CI 95\%) from 6 treatments (Shang et al., 2005; OP. Cit. Bagherian et al, 2014).

Furthermore, Billy (2009) has also reported the efficacy of treatment in patients suffering from ADHD, and Naude, Couchman and Maharaj (2010) have reported the same results in treating the patients with sleep disorders, using homeopathic drugs (OP. Cit. Bagherian et al., 2014). Studies by Viksveen \& Relton (2014), also show the efficacy of homeopathic drugs in treating depression. The effectiveness of homeopathic treatment has also been confirmed in some psychological disorders, like chronic insomnia (Naude et al., 2010). This kind of therapy has also proved effective in treating depression (Viksveen, 2014). Bagherian et al. (2014) have also reported the efficacy of homeopathic treatment in anxiety disorders and depression.

Voluntary service work: Although, there are many researches which have cited indirectly or deeply the importance and effectiveness of voluntary service work on well-being and to boost many psychological and emotional level of health, there is no discrete item to pointing out its effects on improving self-esteem.

\section{Limitations}

In the present study, although the subjects were randomly selected from among volunteers and were also randomly divided into three different groups, all the individuals were normal people, aged between 16 and 40 years old. So, to generalized our results, more research needs to be done in all walks of life. In this study, the population of women was more than men, and the results of the study were limited to only one city.

\section{Directions for the Future}

Since self-esteem is a decisive factor in shaping children's personality, academic achievement, career advancement, communication and satisfaction with life, so, we need more studies in this field to find more effective ways to improve it. And also, because all three testing methods were effective in improving self-esteem, it is recommended to study these methods among different populations and cultures, as well as other segments of society. It is further recommended to pay more attention to homeopathic therapy as an uncomplicated and safe treatment in addition to improving lifestyle for enhancing the people's sense of recovery and raising self-esteem. Life-skills training and creating the spirit of serving the people can have significant results in promoting mental health, which requires further studies and research.

\section{Conflict of Interests}

There is no conflict of interests, and the present study has done based on ethical con- 
sideration and consent.

\section{References}

Adler, U. C., Kruger, S., Teut, M., Ludtke, R., Schutzler, L., Martins, F., Willich, S. N., Linde, K., \& Witt, C. M. (2013). Homeopathy for Depression: A Randomized, Partially Double-Blind, Placebo-Controlled, Four-Armed Study. Plos One, 8, e74537. https:/doi.org/10.1371/journal.pone.0074537

Amozade, M. H. (2012). The Relationship between Low Assertiveness, Self-Esteem, Self-Efficacy, and Self-Assertiveness with Social Anxiety. New Findings in Psychology, 24, 35-56.

Bagherian, M., Kraskian Mojembari, A., \& Hakami, M. (2014). The Effects of Homeopathic Medicines on Reducing the Symptoms of Anxiety and Depression: Randomized, Double Blind and Placebo Controlled. Homeopathy \& Ayurvedic Medicine, 3, 167-170.

Berk, L. (2007). Devalopment through the Lifespan. Y. S. Mohammadi (Translated), 23th Edition, Arasbaran Publishing.

Biabangard, E. (1994). Methods Using to Improve Children and Adults Self-Esteem. Teachers and Parents Association Publishing.

Davidson, J. R., Morrison, R. M., Shore, J., Davidson, R. T., \& Bedayn, G. (2012). Homeopathic Treatment of Depression and Anxiety. Alternative Therapies in Health and Medicine, 3, 46-49.

Frass, M., Friehs, H., Thallinger, C., Sohal, N. K. et al. (2015). Influence of Adjunctive Classical Homeopathy on Global Health Status and Subjective Wellbeing in Cancer Patients-A Pragmatic Randomized Controlled Trial. Complementary Therapies in Medicine, 23, 309-317. https:/doi.org/10.1016/j.ctim.2015.03.004

Galanakis, M., Palaiologou, A., Patsi, G., Velegraki, I.-M., \& Darviri, C. (2016). A Literature Review on the Connection between Stress and Self-Esteem. Psychology, 7, 678-694. https:/doi.org/10.4236/psych.2016.75071

Ghanbarinezhad, M., \& Zarinbakhsh, M. R. (2015). The Relationship between Self-Esteem, Perfectionism and Body Image. International Conference of Future Research on Social Science (CIVILICA).

Ghasemizad, A., Tabrizi Baranjian, H., Abedi, M., \& Barzideh, O. (2000). Relationship between Life Style, Self-Esteem, Stress, Social Investment and Control among Shahed Children. New Findings in Management, 4, 107-124.

Greenwald, A. G., Bellezza, F. S., \& Banaji, M. R. (1988). Is Self-Esteem a Central Ingredient of the Self-Concept? Personality and Social Psychology Bulletin, 3, 34-45. https:/doi.org/10.1177/0146167288141004

Hahnemann, S. (2006). Organon of Medicine. Berkeley, CA: International University Publishing.

Hamann, J., Lind, K., Schweiger, H.-D., Kusmakow, O., \& Forstl, H. (2014). Over-the-CounterDrugs for Treatment of Mood and Anxiety Disorders-The View of German Pharmacists. New York: Georg Thieme verlag KG Stuttgart.

Khan, A., Fleva, E., \& Qazi, T. (2015). Role of Self-Esteem and General Self-Efficacy in Teachers' Efficacy in Primary Schools. Psychology, 6, 117-125. https:/doi.org/10.4236/psych.2015.61010

Montanaro, F., \& Coppola, L. (2013). Effect of a Homeopathic-Complex Medicine on State and Trait Anxiety and Sleep Disorders: A Retrospective Observational Study. Homeopathy, 102, 254-261. https:/doi.org/10.1016/j.homp.2013.07.002

Rhodewalt, F., Madrian, J. C., \& Cheney, S. (1998).Narcissism, Self-Knowledge Organization, and Emotional Reactivity: The Effect of Daily Experiences on Self-Esteem and Affect. Personality and Social Psychology Bulletin, 24, 75-87. https:/doi.org/10.1177/0146167298241006 
Shamloo, S. (1990). Mental Health. Roshd Publishing.

Shamloo, S. (2003). Abnormal Psychology. Roshd Publishing.

Shang, A., Huwiter-Muntener, K., Nartey, L., Juni, P., Dorig, S., Sterne, J. A. C., Pewsner, D., \& Egger, M. (2005). Are the Clinical Effects of Homeopathy Placebo Effects? Comparative Study of Placebo-Controlled Trials of Homeopathy and Allopathy. The Lancet, 366, 726-732. https:/doi.org/10.1016/S0140-6736(05)67177-2

Srivastava, R., \& Joshi, S. (2014). Relationship between Self-Concept and Self-Esteem in Adolescents. International Journal of Advanced Research, 2, 36-43.

Viksveen, P., \& Relton, C. (2014). Depression Treated by Homeopaths: A Study Protocol for a Pragmatic Cohort Multiple Randomized Controlled Trial. Homeopathy, 103, 147-152. https:/doi.org/10.1016/j.homp.2014.01.004

Vithoulkas, G., \& Van Woensel, E. (2010). Levels of Health. Athens: International Academy of Classical Homeopathy.

Submit or recommend next manuscript to SCIRP and we will provide best service for you:

Accepting pre-submission inquiries through Email, Facebook, LinkedIn, Twitter, etc. A wide selection of journals (inclusive of 9 subjects, more than 200 journals)

Providing 24-hour high-quality service

User-friendly online submission system

Fair and swift peer-review system

Efficient typesetting and proofreading procedure

Display of the result of downloads and visits, as well as the number of cited articles Maximum dissemination of your research work

Submit your manuscript at: http://papersubmission.scirp.org/

Or contact psych@scirp.org 